\title{
Influence of Heating Rate on the Transformation Temperature Change in Se- lected Steel Types
}

Jaromír Moravec, Iva Nováková, Jiř́ Vondráček

Technical University of Liberec. Studentská 2, 46117 Liberec 1. Czech Republic. E-mail: jaromir.moravec@tul.cz

The paper is focused on the polymorphic transformations of selected steel types. Generally, when creating CCT diagrams, the transformation temperature values $A_{c 1}$ and $A_{c 3}$ are determined under at very low heating rates $\left(\max .0 .1^{\circ} \mathrm{C} \cdot \mathrm{s}^{-1}\right)$. The only exceptions are so-called in-situ CCT diagrams, which are determined based upon the real temperature cycles. However, in the case of dynamic processes such as welding technology or heat treatment with magnetic induction heating, cannot be used information from conventional CCT diagrams. Incorrectly selected temperatures lead either to incomplete austenitizing during heat treatment or to a different development of phase transformations in HAZ of welds. Especially, when these processes are carried out without soaking temperature. That is why as the main aim of this paper was to determine the heating rate influence for steels $\mathrm{S} 460 \mathrm{MC}$, S690QL and X23CrMoV12-1 on the shift of their transformation temperatures Ac1 and Ac3. The intensity of the heating rate effect on the transformation temperature depends on the steel structure and amount of alloying elements. Consequently, steels with different structures, different type of processing and mechanical properties were deliberately selected to make the assessment as complex as possible.

Keywords: Thermal cycle, Heating rate, Transformation temperature, CCT diagram, S460MC, S700MC, S690QL, $\mathrm{X} 23 \mathrm{CrMoV} 12-1$

\section{Introduction}

Technological processes using high heating rates are during heating phase influenced by the shift of transformation temperatures. Such shift can cause both an insufficient austenitizing in the desired crosssection of heated specimen and different distribution of structural phases in the heat affected zone (HAZ) of weld joints. Both of these aspects result in change of finally achieved structural and mechanical properties. $[1,2,3]$

When heating materials that allow polymorphic lattice transformation (defined by a temperature interval), the energy available to rearrange atoms into a new lattice type is not high enough at the start of transformation. Therefore, phases or components requiring the least amount of energy for lattice transformation are preferably transformed. As the temperature increases, the amount of energy in the system increases as well and other material phases or components also gradually transform into the FCC. However, these transformations need sufficient time to take place in the whole volume. At higher heating rates, there isn't provide to system enough time to transform the lattice at given temperature [1]. That is why transformation processes are realized only when higher energy is supplied; thus at higher temperatures. [4] How intensively the heating rate affects the transformation temperatures depends, among others, on the initial steel structure and the amount of alloying elements.
Consequently, steels with different structures, manufacturing and processing as well as with different mechanical properties were intentionally selected. Steel S460MC is thermo-mechanically processed finegrained ferritic-pearlitic material. Steel S690QL is also fine-grained, but due to another production method (refining) it has different chemical composition and its structure also contains tempered bainite in its basic state. They differ both in higher carbon content and in other alloying elements such as $\mathrm{Cr}, \mathrm{Mo}$ and possibly also Ni. [5] Martensitic chromium steel X23CrMoV12-1 then differs from previous materials in all aspects, so both in structure, quantity of alloying elements and mechanical properties - especially at elevated temperatures.

In addition to all mentioned knowledge above, the method of used heating, dimensions and shape of the test specimen also have the influence on the transformation temperatures values and the accuracy of dilatometry measurements [6]. This statement concerns both the generating CCT diagrams and the assessment of the heating rate influence on transformation processes. [7, 8] All experiments described in the following chapters were carried out using the quenching dilatometer DIL805L from company TA Instrument. The dilatometer uses controlled heating by magnetic induction realized by a heating coil.

2 Objectives of the experimental part and used materials

One main and several partial objectives were set 
for the experimental activity. Based upon of them there was possible to prepare the experimental plan. The main objective was to assess the influence of heating rate on the shift of transformation temperatures $A_{c 1}$ and $A_{c 3}$ vales for selected steel types. Partial objectives were to assess the possibility of repeated measurement of transformation temperatures on the same specimen. As a reason there was the unambiguous definition of the experimental boundary conditions at multiple measurements. Another partial objective was to assess the possibility of using quenching dilatometer DIL 805L for dilatometry measurements realized for heating and cooling rates corresponding to real welding cycles. Thus, the assessment of utilization the mentioned dilatometer in generating in situ CCT diagrams. This was also related to the last partial objective that concerned about determination the critical heating rate for the dilatometer DIL 805L. By this is meant the maximum heating rate at which it is still possible to deduct from the dilatometry curve all required information with sufficient accuracy.

Three types of steel marked acc. To ISO 10027-1 as S460MC, S690QL and X23CrMoV12-1 were selected for the experimental part. Reasons of such selection were mentioned in the introduction of this paper.

The S460MC is structural, micro-alloyed and finegrained steel made by the thermo-mechanical rolling. It has minimal guaranteed yield strength of $460 \mathrm{MPa}$ and is guaranteed to be weldable. It is used for cold formed products, most often as stampings or sheets for structural assemblies. The steel is micro-alloyed with Ti, Al, Nb and $\mathrm{V}$ and in basic state is ferriticpearlitic. Tab. 1 shows both the chemical composition of steel S460MC acc. to EN 10149 and the actual composition determined by spectrometer Tasman Q4. Tab. 2 shows the basic mechanical properties of steel $\mathrm{S} 460 \mathrm{MC}$ as determined by the static tensile test. These are average values from five measurements.

Tab. 1Chemical composition of S460MC (wt\%) - acc. to CSN EN 10149 and measured by Q4Tasman spectrometer

\begin{tabular}{|c|c|c|c|c|c|c|c|c|c|}
\hline & C & Si & Mn & P & S & Al & Nb & V & Ti \\
\hline EN 10149 & 0.12 & 0.5 & 1.6 & 0.025 & 0.015 & 0.015 & 0.09 & 0.20 & 0.15 \\
\hline Q4 Tasman & 0.072 & 0.012 & 1.324 & 0.029 & 0.008 & 0.031 & 0.051 & 0.080 & 0.004 \\
\hline
\end{tabular}

Tab.2 Material S460MC - mechanical properties

\begin{tabular}{|c|c|c|c|c|}
\hline \multirow{3}{*}{ S460MC } & $\begin{array}{c}\text { Yield Strength } \\
\mathbf{R}_{\mathbf{e}}[\mathbf{M P a}]\end{array}$ & $\begin{array}{c}\text { Ultimate Strength } \\
\mathbf{R}_{\mathrm{m}}[\mathbf{M P a}]\end{array}$ & $\begin{array}{c}\text { Uniform Ductility } \\
\mathbf{A}_{\mathbf{g}}[\mathbf{\%}]\end{array}$ & $\begin{array}{c}\text { Total Ductility } \\
\mathbf{A}_{\mathbf{3 0}}[\mathbf{\%}]\end{array}$ \\
\cline { 2 - 5 } & 541 & 630 & 13.16 & 29.59 \\
\hline
\end{tabular}

Steel S690QL is structural, high-strength, heattreated material. It has minimal guaranteed yield strength of $690 \mathrm{MPa}$ and strength value varies between 770 - $940 \mathrm{MPa}$ depending on the material thickness. It reveals good weldability with sufficient formability. The hardenability of the material at higher thicknesses is given due to the higher $\mathrm{Cr}$ and even. also $\mathrm{Ni}$ contents. It is used for the machine parts design, where is necessary to reduce weight while maintaining strength conditions. Its basic state is usually as tempered bainite. Tab. 3 shows the chemical composition of steel S690QL acc. to the standard EN 10149, as well as the actual chemical composition determined by spectrometer Tasman Q4. Tab. 4 then summarizes the basic mechanical properties of S690QL steel.

Tab. 3 Chemical composition of S690QL (wt\%) - acc. to CSN EN 10149 and measured by Q4Tasman spectrometer

\begin{tabular}{|c|c|c|c|c|c|c|c|c|c|}
\hline & $\mathbf{C}$ & $\mathbf{S i}$ & $\mathbf{M n}$ & $\mathbf{P}$ & $\mathbf{S}$ & $\mathbf{C r}$ & $\mathbf{M o}$ & $\mathbf{N i}$ & $\mathbf{V}$ \\
\hline EN 10149 & 0.20 & 0.80 & 1.70 & 0.02 & 0.01 & 1.50 & 0.70 & 2.00 & 0.12 \\
\hline Q4 Tasman & 0.192 & 0.272 & 0.990 & 0.024 & 0.006 & 0.619 & 0.213 & 0.013 & 0.034 \\
\hline
\end{tabular}

Tab.4 Material S690QL - mechanical properties

\begin{tabular}{|c|c|c|c|c|}
\hline \multirow{3}{*}{ S460MC } & $\begin{array}{c}\text { Yield Strength } \\
\mathbf{R}_{\mathrm{e}}[\mathbf{M P a}]\end{array}$ & $\begin{array}{c}\text { Ultimate Strength } \\
\mathbf{R}_{\mathbf{m}}[\mathbf{M P a}]\end{array}$ & $\begin{array}{c}\text { Uniform Ductility } \\
\mathbf{A}_{\mathbf{g}}[\mathbf{\%}]\end{array}$ & $\begin{array}{c}\text { Total Ductility } \\
\mathbf{A}_{\mathbf{3 0}}[\mathbf{\%}]\end{array}$ \\
\cline { 2 - 5 } & 834 & 881 & 7.12 & 17.93 \\
\hline
\end{tabular}

Steel X23CrMoV12-1 is in accordance with the standard CSN EN 10302 classified into the group 9 $12 \% \mathrm{Cr}$ of martensitic steels. It is high-alloy stainless steel designed for applications at temperatures up to $650{ }^{\circ} \mathrm{C}$. It is often used for steam turbine components such as blades, rotors and compressors. However, it can be used also in other different applications with high working temperatures, such as aircraft propulsion. Tab. 5 shows the chemical composition of steel $\mathrm{X} 23 \mathrm{CrMoV} 12-1$ as determined by spectrometer Tasman Q4. In Tab. 6 are shown the basic mechanical properties of steel X23CrMoV12-1 in basic tempered state. 
Tab. 5 Chemical composition of X23CrMoV12-1 (wt\%) - measured by Q4Tasman spectrometer

\begin{tabular}{|c|c|c|c|c|c|c|c|c|c|c|}
\hline $\mathbf{C}$ & $\mathbf{S i}$ & $\mathbf{M n}$ & $\mathbf{P}$ & $\mathbf{S}$ & $\mathbf{C r}$ & $\mathbf{M o}$ & $\mathbf{N i}$ & $\mathbf{V}$ & $\mathbf{W}$ & $\mathbf{C u}$ \\
\hline 0.238 & 0.360 & 0.609 & 0.048 & 0.013 & 11.82 & 1.148 & 1.151 & 0.301 & 0.131 & 0.092 \\
\hline
\end{tabular}

Tab.6 Material X23CrMoV12-1 - mechanical properties

\begin{tabular}{|c|c|c|c|c|}
\hline $\begin{array}{c}\text { X23CrMoV12- } \\
1\end{array}$ & $\begin{array}{c}\text { Yield Strength } \\
\mathbf{R}_{\mathbf{e}}[\mathbf{M P a}]\end{array}$ & $\begin{array}{c}\text { Ultimate Strength } \\
\mathbf{R}_{\mathbf{m}}[\mathbf{M P a}]\end{array}$ & $\begin{array}{c}\text { Uniform Ductility } \\
\mathbf{A}_{\mathbf{g}}[\mathbf{\%}]\end{array}$ & $\begin{array}{c}\text { Total Ductility } \\
\mathbf{A}_{\mathbf{3 0}}[\mathbf{\%}]\end{array}$ \\
\cline { 2 - 5 } & 598 & 823 & 9.73 & 19.34 \\
\hline
\end{tabular}

\section{Experimental part}

In the first phase was tested whether the same transformation temperatures were reached by repeated heating of the same sample by a defined temperature cycle or whether the previous thermal influence of the sample significantly affected the new measurement. Unless no influence on the dilatometry curves is found, it will greatly save the time required in practice for the individual tests measurements. The experiments were performed on S690QL steel at heating rate of $0.15{ }^{\circ} \mathrm{C} \cdot \mathrm{s}^{-1}$ to temperature $1000{ }^{\circ} \mathrm{C}$, soaking time 60 seconds was followed by cooling at $10^{\circ} \mathrm{C} \cdot \mathrm{s}^{-1}$. Totally, measurements were repeated 3 times. The soaking temperature was chosen at such magnitude, at which did not occur grain growth in the test specimens [9]. To ensure complete repeatability of the boundary conditions, the test specimen was subjected to a temperature cycle with maximum temperature $1000{ }^{\circ} \mathrm{C}$ and cooling rate $10{ }^{\circ} \mathrm{C} \cdot \mathrm{s}^{-1}$ prior to the first measurement. As a result, the same structure of the test specimen was achieved already before the first measurement.

The "Tangents method" and the "1st Derivative method" were used for the evaluation. The principle of determination transformation temperatures by means of tangents is shown in Fig. 1. When evaluating by the "1st Derivative method", it is necessary to differentiate the measured dilatometry curve by temperature. As a result, there is dilation rate curve of specimen in the dependence on temperature. Transformation temperatures are then determined at areas, where the dilation rate equals zero [10]. The graphical determination of transformation tangents by the " 1 st Derivative method" is shown in Fig. 2. Tab. 7 illustrates the transformation temperatures $\mathrm{Ac}_{1}$ and $\mathrm{Ac}_{3}$ obtained from evaluation by both used methods.

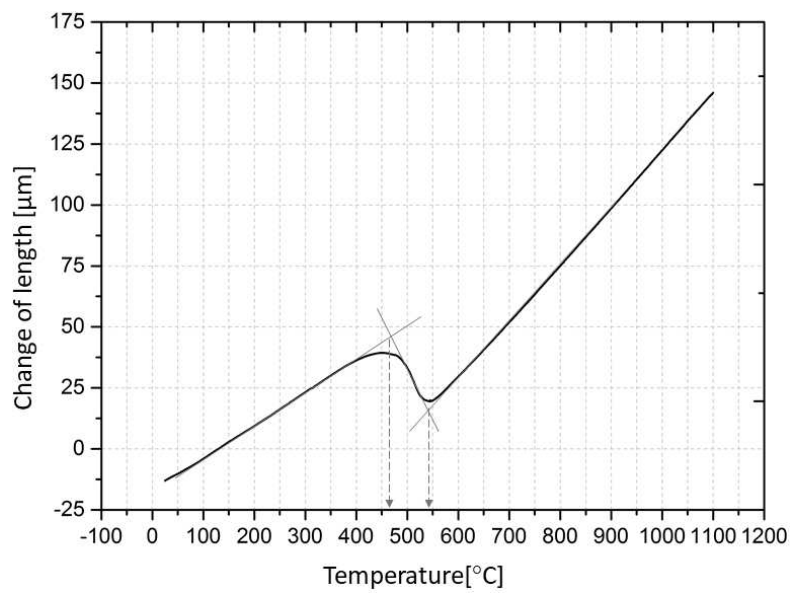

Fig. 1 Determination of transformation temperatures ,Tangents method"

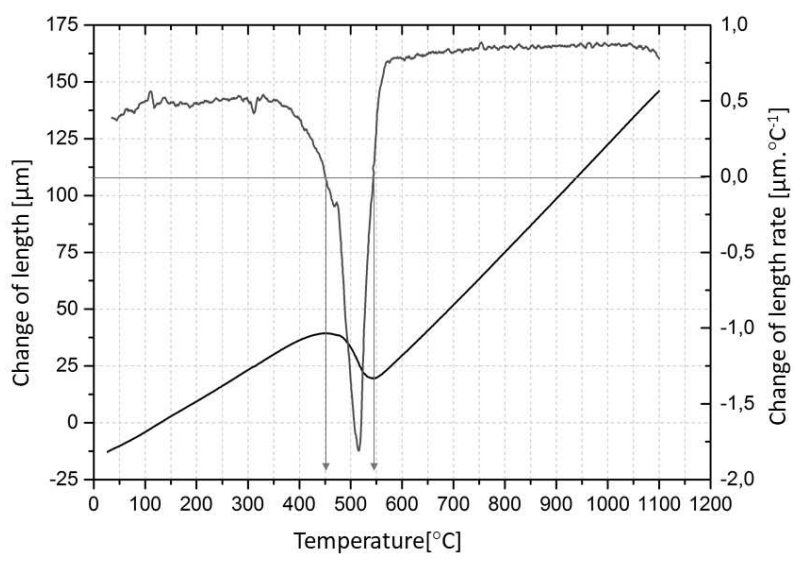

Fig. 2 Determination of transformation temperatures ,, $1^{\text {st }}$ Derivation method"

Tab. 7 Transformation temperatures $A_{c 1}$ a $A_{c 3}$ obtained from measurement the same specimen - S690QL

\begin{tabular}{|c|c|c|c|c|c|c|}
\hline $\begin{array}{c}\text { No. of } \\
\text { measure- } \\
\text { ment }\end{array}$ & \multicolumn{3}{|c|}{ Temperature $\boldsymbol{A}_{\boldsymbol{C 1}}{ }^{\left.{ }^{\circ} \mathbf{C}\right]}$} & \multicolumn{3}{c|}{ Temperature $\left.\boldsymbol{A}_{\boldsymbol{C} \mathbf{}}{ }^{\circ} \mathbf{C}\right]$} \\
\hline $\mathbf{3}$ tangents & $\mathbf{1}^{\text {st }}$ derivate & Average & 3 tangents & 1 $^{\text {st }}$ derivate & Average \\
\hline $\mathbf{1}$ & 757 & 754 & 755.5 & 838 & 834 & 836 \\
\hline $\mathbf{2}$ & 758 & 757 & 757.5 & 838 & 834 & 836 \\
\hline $\mathbf{3}$ & 760 & 758 & 759 & 842 & 838 & 840 \\
\hline
\end{tabular}

The second part of the experiment was devoted to the assessment of the heating rate influence on the transformation temperatures $\mathrm{Ac}_{1}$ and $\mathrm{Ac}_{3}$. In the first stage were selected heating rates as following: $0.1 ; 1$; $10 ; 100$ and $500{ }^{\circ} \mathrm{C} \cdot \mathrm{s}^{-1}$. These were firstly applied to S690QL steel. At heating rate $500{ }^{\circ} \mathrm{C} \cdot \mathrm{s}^{-1}$ was possible 
to determine transformation temperatures by the tangents method, but not anymore by the 1 st derivation method. As a reason, there was the shape of measured dilatometry curve - see Fig. 3.

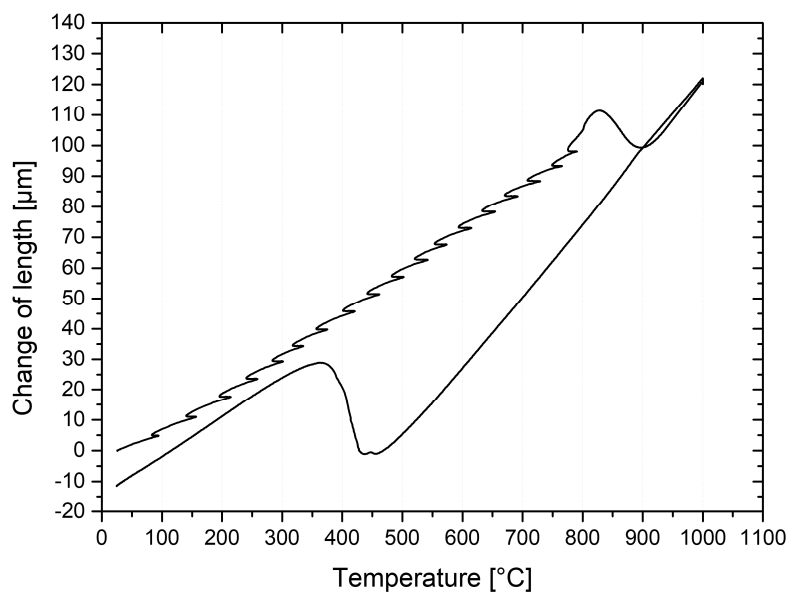

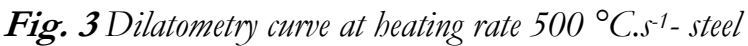
S690QL

The obtained curve is no longer smoothly continuous due to insufficiently fast compensation of the induction coil power that was used for specimen heating. From derivations is then obtained quite a lot of minima and it is necessary to manually select the appropriate transformation temperature. Therefore, another measurement was performed with a heating rate of $250{ }^{\circ} \mathrm{C} \cdot \mathrm{s}^{-1}$, which provided better results. However, the dilatometry curve wasn't still smoothly continuous. The same was valid for the heating rate of $150{ }^{\circ} \mathrm{C} \cdot \mathrm{s}^{-1}$, see Fig. 4. As a critical magnitude was finally determined heating rate of $100{ }^{\circ} \mathrm{C} \cdot \mathrm{s}^{-1}$, when achieved dilatation curve was already smoothly continuous. Tab. 9 shows values of evaluated transformation temperatures for all applied heating rates.

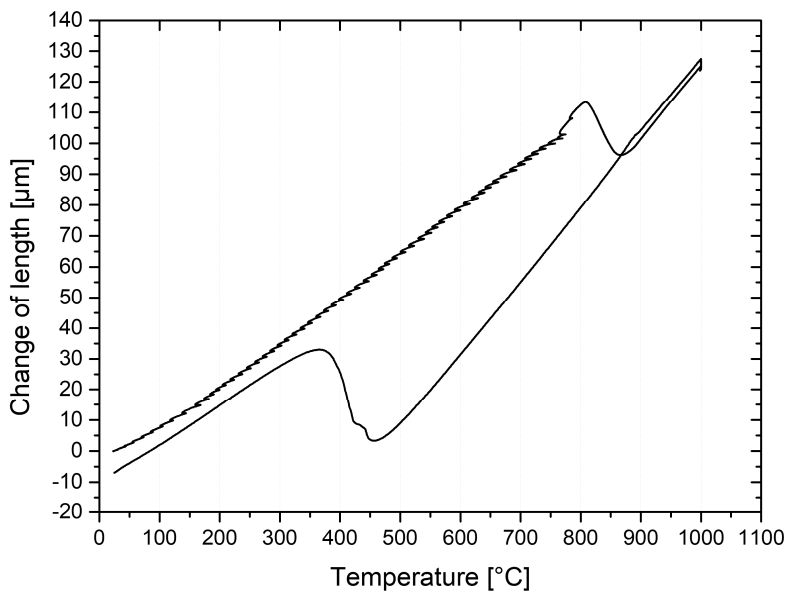

Fig. 4 Dilatometry curve at heating curve $150^{\circ} \mathrm{C} .5^{-1}$ - steel S690QL

Tab. 8 Transformation temperatures $A_{c 1}$ and $A_{c 3}$ measured at different heating rates - S690QL

\begin{tabular}{|c|c|c|c|c|c|c|c|}
\hline \multirow{2}{*}{$\begin{array}{l}\text { Measure- } \\
\text { ment }\end{array}$} & \multirow{2}{*}{$\begin{array}{c}\text { Heat } \\
\text { Rate } \\
{\left[{ }^{\circ} \mathrm{C.s}^{-1}\right]}\end{array}$} & \multicolumn{3}{|c|}{ Temperature $\boldsymbol{A}_{\boldsymbol{C} 1}\left[{ }^{\circ} \mathrm{C}\right]$} & \multicolumn{3}{|c|}{ Temperature $A_{C 3}\left[{ }^{\circ} \mathrm{C}\right]$} \\
\hline & & 3 tangents & $\begin{array}{c}1^{\text {st }} \text { deri- } \\
\text { vate }\end{array}$ & Average & 3 tangents & $\begin{array}{c}1^{\text {st }} \text { deri- } \\
\text { vate }\end{array}$ & Average \\
\hline 1 & 0.1 & 750 & 748 & 749 & 839 & 835 & 837 \\
\hline 2 & 1 & 754 & 744 & 749 & 830 & 830 & 830 \\
\hline 3 & 10 & 770 & 767 & 768.5 & 841 & 840 & 840.5 \\
\hline 4 & 100 & 802 & 800 & 802.5 & 857 & 860 & 858.5 \\
\hline 5 & 150 & 811 & $804 *$ & 807.5 & 868 & $868^{*}$ & 868 \\
\hline 6 & 250 & 819 & $810^{*}$ & 814.5 & 879 & $883^{*}$ & 881 \\
\hline 7 & 500 & 832 & $829 *$ & 830.5 & 900 & $898^{*}$ & 899 \\
\hline
\end{tabular}

Tab. 9 Transformation temperatures $A_{c 1}$ and $A_{c 3}$ measured at different heating rates - S460MC

\begin{tabular}{|c|c|c|c|c|c|c|c|}
\hline \multirow{2}{*}{$\begin{array}{c}\text { Measure- } \\
\text { ment }\end{array}$} & $\begin{array}{c}\text { Heat } \\
\text { Rate } \\
{\left[{ }^{\circ} \mathbf{C . s}{ }^{-1}\right]}\end{array}$ & \multicolumn{2}{|c|}{ Temperature $\left.\boldsymbol{A}_{\boldsymbol{C 1}}{ }^{\circ}{ }^{\circ} \mathbf{C}\right]$} & \multicolumn{3}{c|}{ Temperature $\boldsymbol{A}_{\boldsymbol{C 3}}\left[{ }^{\circ} \mathbf{C}\right]$} \\
\hline $\mathbf{1}$ & $\mathbf{0 . 1}$ & 736 & 732 & 734 & 870 & 872 & 871 \\
\hline $\mathbf{2}$ & $\mathbf{1}$ & 732 & 732 & 732 & 861 & 863 & 862 \\
\hline $\mathbf{3}$ & $\mathbf{1 0}$ & 750 & 748 & 749 & 879 & 882 & 880.5 \\
\hline $\mathbf{4}$ & $\mathbf{1 0 0}$ & 784 & 793 & 788.5 & 896 & 899 & 897.5 \\
\hline
\end{tabular}


Tab. 10 Transformation temperatures $A_{c 1}$ and $A_{c 3}$ measured at different heating rates - X23CrMoV12-1

\begin{tabular}{|c|c|c|c|c|c|c|c|}
\hline \multirow{2}{*}{$\begin{array}{c}\text { Measure- } \\
\text { ment }\end{array}$} & \multirow{2}{*}{$\begin{array}{c}\text { Heat } \\
\text { Rate } \\
{\left[{ }^{\circ} \mathrm{C} . \mathrm{s}^{-1}\right]}\end{array}$} & \multicolumn{3}{|c|}{ Temperature $\boldsymbol{A}_{\boldsymbol{C} 1}\left[{ }^{\circ} \mathrm{C}\right]$} & \multicolumn{3}{|c|}{ Temperature $A_{C 3}\left[{ }^{\circ} \mathrm{C}\right]$} \\
\hline & & 3 tangents & $\begin{array}{c}1^{\text {st }} \text { deri- } \\
\text { vate }\end{array}$ & Average & 3 tangents & $\begin{array}{l}1^{\text {st }} \text { deri- } \\
\text { vate }\end{array}$ & Average \\
\hline 1 & 0.1 & 809 & 804 & 806.5 & 854 & 853 & 853.5 \\
\hline 2 & 1 & 840 & 836 & 838 & 887 & 889 & 888 \\
\hline 3 & 10 & 878 & 874 & 876 & 925 & 923 & 924 \\
\hline 4 & 100 & 913 & 918 & 915.5 & 978 & 970 & 974 \\
\hline
\end{tabular}

Due to the determination critical heating rate at magnitude $100{ }^{\circ} \mathrm{C} \cdot \mathrm{s}^{-1}$, for the two remaining steels (S460MC and X23CrMoV12-1) were used heating rates as following: $0.1 ; 1 ; 10$ and $100{ }^{\circ} \mathrm{C} \cdot \mathrm{s}^{-1}$. Measured results for material S460MC are shown in Tab. 9 and for creep-resistance steel X23CrMoV12-1 in Tab. 10

\section{Conclusion}

The paper dealers with the assessment of heating rate influence on the transformation temperatures change at selected types of steel. Results from the performed experimental measurements can be summarized as following:

- Performing repeated dilatometry measurements on one specimen can be carry out with sufficient accuracy. The maximum difference between individual measurements did not exceed $4{ }^{\circ} \mathrm{C}$ for both evaluation methods. However, from the successive measurements is obvious trend of slight increase in transformation temperature. Therefore, always new sample was used for each measurement.

- Dilatometry measurements can be performed on quenching dilatometer DIL 805L with heating rates exceeding $500{ }^{\circ} \mathrm{C} \cdot \mathrm{s}^{-1}$. So it can be also used for measuring in situ CCT diagrams. Nevertheless, it is important to note that at heating rates exceeding $100{ }^{\circ} \mathrm{C} \cdot \mathrm{s}-$ 1 is not possible to achieve a smoothly continuous dilatometry curve. This considerably complicates the evaluation of transformation temperatures by the $1^{\text {st }}$ deformation method. Therefore, heating rate at $100 \mathrm{C} \cdot \mathrm{s}^{-1}$ was evaluated as the so-called critical heating rate.

- Transformation temperatures $A_{c 1}$ and $A_{c 3}$ are determined under very slow heating rates when generating CCT diagrams, generally not exceeding heating rate of ${ }^{\circ} \mathrm{C} \cdot \mathrm{s}^{-1}$. It has been found that increasing heating rate has an effect on the shift of transformation temperatures $A_{c 1}$ and $A_{c 3}$ towards higher values. This effect increases with the higher amount of alloying elements. For material S460MC was temperature $A_{c 1}$ shifted by more than $50^{\circ} \mathrm{C}$ and $34^{\circ} \mathrm{C}$ in the case of $\mathrm{A}_{\mathrm{c} 3}$ when the sample was heated at $100{ }^{\circ} \mathrm{C} \cdot \mathrm{s}^{-1}$. It was similar for S690QL steel. In addition to that, for steel S690QL was found that at heating rate $500 \quad{ }^{\circ} \mathrm{C} \cdot \mathrm{s}^{-1}$ was transformation temperature $\mathrm{A}_{\mathrm{c} 1}$ shifted by $82{ }^{\circ} \mathrm{C}$ and $\mathrm{A}_{\mathrm{c} 3}$ by $42{ }^{\circ} \mathrm{C}$. The greatest shifts of transformation temperatures occurred in the case of martensitic steel X23CrMoV12-1. There was shift by $109^{\circ} \mathrm{C}$ for $\mathrm{A}_{\mathrm{c} 1}$ and by $120^{\circ} \mathrm{C}$ for $\mathrm{A}_{\mathrm{c} 3}$.

It has been experimentally confirmed that the heating rate significantly affects the transformation temperatures $A_{c 1}$ and $A_{c 3}$, especially in high-alloy steels. Therefore, in dynamic processes such as welding technology or heat treatments, it is not possible to rely only on information from classical CCT diagrams [2]. Incorrectly selected temperatures lead either to incomplete austenitizing during heat treatment or to other evolution of phase transformations in HAZ of welds. Especially, when these processes take place without the soaking temperature.

\section{Acknowledgement}

This publication was written at the Technical University of Liberec as part of the project SGS 21280 "Research and development for innovation of materials and production technologies with application potential in mechanical engineering" with the support of the Specific University Research Grant, as provided by the Ministry of Education, Youth and Sports of the Czech Republic in the year 2020.

\section{References}

[1] ORAVCOVÁ, M., PALČEK, P., KRÓL, M. (2016). Dilatometric Measurements of Austenitic Stainless Steel as a Function of Temperature. 
In: Manufacturing Technology, Vol. 16, No. 1, pp. 230-234, UJEP. Czech Republic.

[2] GOLDSTEIN, R., BUCHNER, E., CRYDERMAN, R. (2018) Modeling of Short Time Dilatometry Testing of High Carbon Steels. In: Proceedings of the 29th ASM Heat Treating Society Conference. p. 24-26.

[3] GODIN, H., et al. (2019) Effects of cooling path and resulting microstructure on the impact toughness of a hot stamping martensitic stainless steel. In: Materials Science and Engineering $A$, Vol. 742, pp. 597-607.

[4] PEKOVIČ, M., VOREL, I., KÁŇA, J., OPATOVÁ, K. (2017) Evolution of Microstructure and Mechanical Properties in Steels during Isothermal Holding in the Region of Bainitic Transformation Temperature in Dependence on Silicon Content. In: Manufacturing Tecbnology, Vol. 17, No. 4, pp. 549-555, UJEP. Czech Republic.

[5] KUČEROVÁ, L., BYSTRIANSKÝ, M., JENÍČEK, Š. (2019) Thermo-mechanical Treatment of 0.4C-0.6Mn-2Si Steel with Various Soaking and Annealing Hold Temperatures. In: Manufacturing Technology, Vol. 19, No. 1, pp. 95100, UJEP. Czech Republic.
[6] MORAVEC, J., DIKOVITS, M., NOVÁKOVÁ, I., CALISKANOGLU, O. (2015). A comparison of dilatometry results obtained by two different devices when generating CCT and in-situ diagrams. In: Key Engineering Materials, Vol. 669, pp. 477 - 484. Trans Tech Publications. Switzerland.

[7] MONDELIN, A. et al. (2014). Characterisation of surface martensite-austenite transformation during finish turning of an AISI S15500 stainless steel. In: International Journal of Machining and Machinability of Materials, Vol. 15, No 1-2, pp. 101-121.

[8] DE ANDRÉS, C. G., et al. (2002). Application of dilatometric analysis to the study of solidsolid phase transformations in steels. In: Materials Characterization, Vol. 48, No. 1, pp. 101-111.

[9] MORAVEC, J., NOVÁKOVÁ, I., SOBOTKA, J., NEUMANN, H. (2019). Determination of grain growth kinetics and assessment of welding effect on properties of S700MC steel in the HAZ of welded joints. In: Metals, 9 (6), MDPI AG.

[10] MOTYČKA, P., KÖVÉR, M. (2012). Evaluation methods of dilatometer curves of phase transformations. In: Recent trends in structural materials, COMAT 2012, Plzeň, Czech Republic. 